\section{CITAÇÃo}

Rosa, F. (2019)

Um parasita pouco conhecido,

Rev. Ciência Elem., V7 (02):026

doi.org/10.24927/rce2019.026

\section{EDITOR}

José Ferreira Gomes,

Universidade do Porto

\section{EDITOR CONVIDADO}

Paulo Fonseca,

Universidade de Lisboa

\section{RECEBIDO EM}

31 de maio de 2019

\section{ACEITE EM}

31 de maio de 2019

\section{PUBLICADO EM}

21 de junho de 2019

\section{COPYRIGHT}

(C) Casa das Ciências 2019.

Este artigo é de acesso livre, distribuído sob licença Creative Commons com a designação CC-BY-NC-SA 4.0, que permite a utilização e a partilha para fins não comerciais, desde que citado o autor e a fonte original do artigo.

rce.casadasciencias.org

\title{
Um parasita pouco conhecido
}

\author{
Fernanda Rosa \\ ISA, CESAM/ Universidade de Lisboa
}

Quando pensamos em parasitas - seres vivos que vivem à custa de outros, prejudicando-os - pensamos nas lombrigas, nas ténias, nos piolhos, nas pulgas e nas carraças, contudo existem muitos outros com ciclos de vida bem distintos, mais ou menos complexos e com necessidade de utilizarem diversos hospedeiros para sobreviverem. Os trematódeos (filo Platyhelminthes) são um grupo de parasitas com um ciclo de vida indireto, necessitando de dois hospedeiros: um vertebrado - hospedeiro definitivo (HD), onde o parasita atinge a maturidade sexual - e um invertebrado - hospedeiro intermediário $(\mathrm{HI})$, no qual o parasita se multiplica assexuadamente, originando um número exponencial de formas infetantes para o HD.

Os esquistossomas (Trematoda, Schistosomatidae) são os únicos parasitas dioicos deste grupo, com a designação genérica de Schistosoma e cujas principais características morfológicas são:

- macho com um corpo foliáceo dobrado sobre si mesmo, formando um canal, o canal ginecóforo, onde a fêmea, filiforme, se aloja (FIGURA 1);

- ovos fusiformes com um esporão bem evidente, em posição terminal (FIGURA 2) ou lateral, na maior parte das espécies.

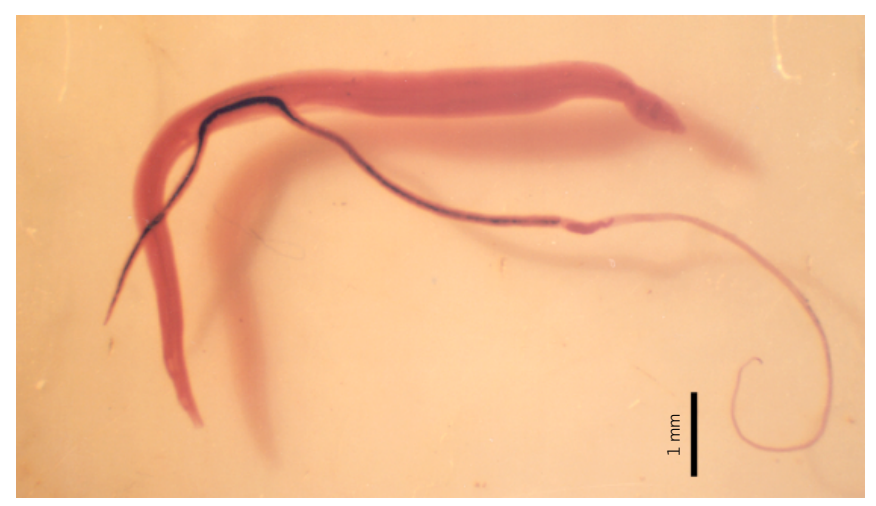

FIGURA 1. Schistosoma bovis (bovino; Guiné-Bissau, 1990): macho e fêmea emparelhados. Coloração com Carmim-alcoólico-clorídrico. 
Conhecem-se 21 espécies em todo o mundo que ocorrem principalmente em regiões tropicais e subtropicais, nomeadamente África, Ásia e no sul da América e da Europa. Estão associadas a coleções de água, onde os moluscos gastrópodes dulçaquícolas, potenciais HI (FIGURA 3), existem. Provocam doenças no HD, homem e/ou animais, mais ou menos graves, de acordo com a localização dos parasitas adultos (FIGURA 4), sendo as formas urogenital e intestinal, as mais frequentes em pacientes humanos. Estas doenças são consideradas pela Organização Mundial de Saúde, como negligenciadas, uma vez que os sintomas são muitas vezes insipientes e inespecíficos e a evolução da doença ocorre normalmente de forma crónica. Por outro lado, os países, onde estas doenças são endémicas, possuem um sistema de saúde muito fragilizado por dificuldades em recursos humanos, técnicos e financeiros.
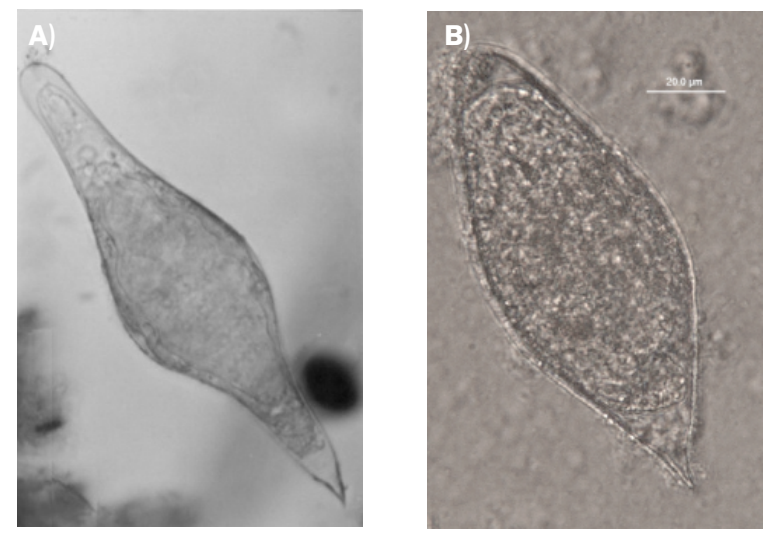

FIGURA 2. Ovos de Schistosoma bovis (A) nas fezes de bovinos (Itha de Santiago, Cabo Verde, 1997) e de S. haematobium (B) na urina de crianças (Guiné-Bissau, 2010).

Em contacto com a água, os hospedeiros vertebrados (primatas, ruminantes domésticos e silvestres, pequenos roedores, entre outros) infetados eliminam os ovos embrionados com as fezes ou com a urina (FIGURA 2).

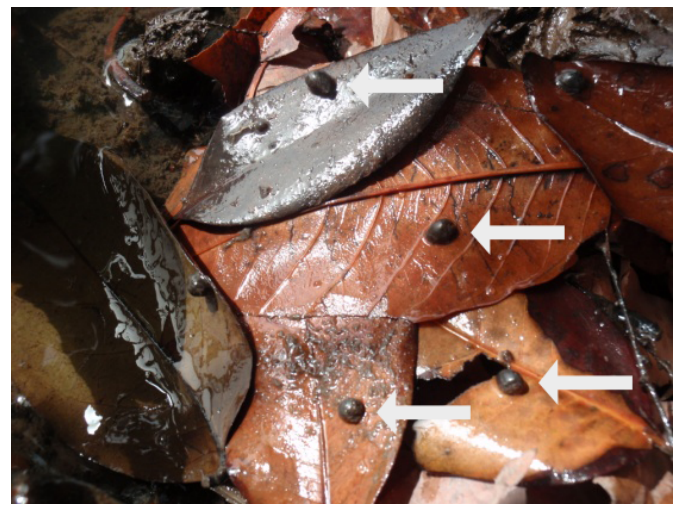

FIGURA 3. Bulinus globosus (setas brancas) na página inferior de folhas em decomposição na água do rio Geba (Cafiá, Guiné-Bissau, 2010).

$\mathrm{Na}$ água, o embrião, denominado miracídio (FIGURA 5), eclode do ovo e nada ativamente à procura de um molusco aquático suscetível. Depois de penetrar o molusco, sofre várias 
modificações morfológicas e fisiológicas, dando origem a várias gerações de esporocistos, onde irão desenvolver-se as cercárias, ou seja, as formas infetantes para o HD (FIGURA 6). Quando estas cercárias atingirem a maturidade, elas abandonam o molusco e nadam à procura de um HD, penetrando-o através da pele. Esta penetração é acompanhada por outras modificações morfológicas e fisiológicas, originando-se a esquistossómula, a qual entra na circulação venosa e migra para o coração, pulmões e fígado do hospedeiro vertebrado infetado. Neste último órgão dá-se o emparelhamento do macho e da fêmea (FIGURA 1) e o casal segue então para a sua morada final, os vasos sanguíneos da bexiga ou do mesentério (intestino).

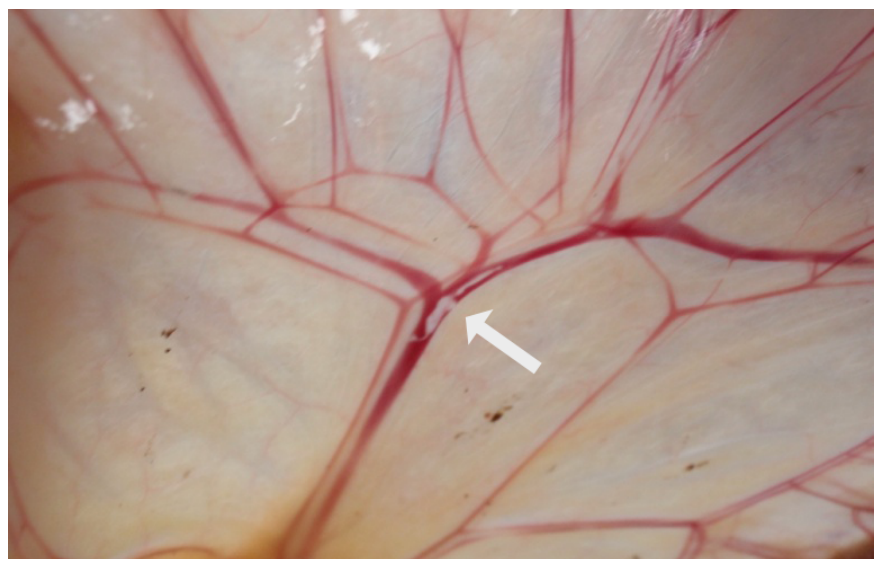

FIGURA 4. Schistosoma bovis (HD, bovino, Guiné-Bissau, 2010) (seta branca): Localização nos vasos sanguíneos do mesentério, macho e fêmea emparelhados.

0 único foco de esquistossomose humana, na Europa, por S. haematobium, foi identificado e estudado no Algarve, por Carlos França, em 1921, e foi considerado extinto por Fraga de Azevedo e seus colaboradores, em 1948.

$\mathrm{Na}$ Europa, descreveu-se ainda focos de esquistossomose animal por S. bovis em ruminantes domésticos e nos moluscos HI, nas regiões da Córsega (França), Sardenha e Sicília (Itália) - Brumpt, em 1929 e 1930 -, e na região de Salamanca (Espanha) - Ramajo-Martin e colaboradores, nas décadas de 70 e 80.

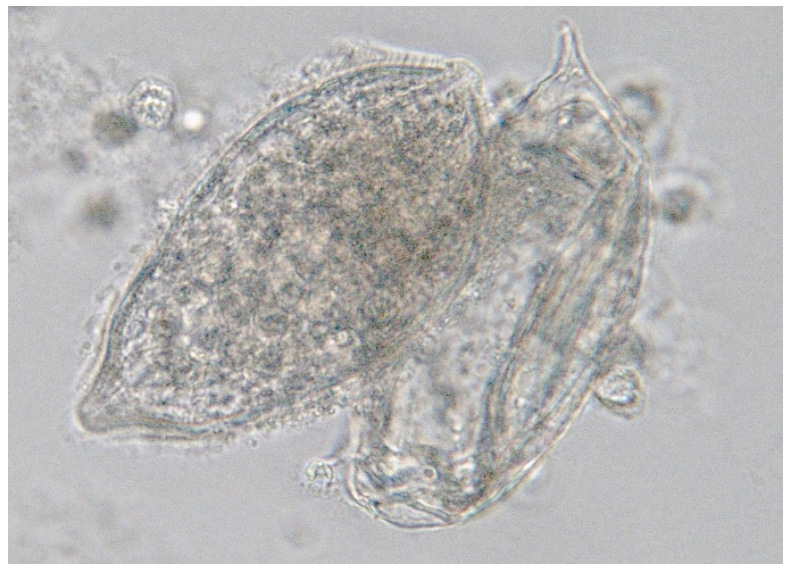

FIGURA 5. Miracídio de S. haematobium a eclodir do ovo (Criança, Guiné-Bissau, 2010). Forma infetante para o invertebrado aquático $\mathrm{HI}$. 
Recentemente, o diagnóstico desta doença em pacientes humanos, que tinham passado férias na região da Córsega e se tinham banhado no rio Cavu, em 2013, permitiu reconhecer um novo foco de esquistossomose humana, que tem vindo a ser estudado por vários investigadores e que tem levantado muita preocupação em saúde pública. Este foco caracterizou-se pelo facto da maioria dos pacientes se encontrarem infetados por híbridos entre S. bovis, espécie autóctone, e S. haematobium, espécie que se suspeita ter sido recentemente introduzida, provavelmente devido ao fluxo de migrantes sul-norte que a Europa e, em particular, aquela zona tem sofrido.

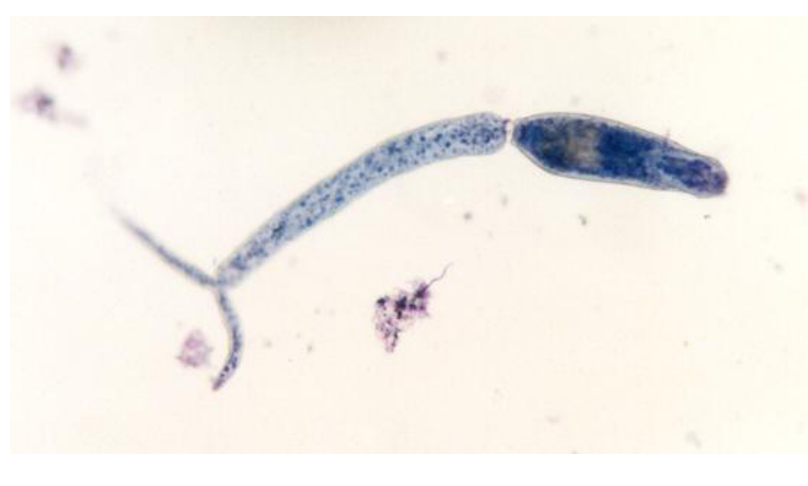

FIGURA 6. Cercária de S. bovis emitida por B. forskalii (Ilha de Santiago, Cabo Verde, 1997). Forma infetante para o vertebrado HD. Coloração vital com azul de metileno.

Acresce mencionar que existe pouca informação sobre os antigos focos de esquistossomose animal, na Europa, sendo esta, associada à infeção humana no rio Cavu (Córsega), a mais recente. É possível que, nas regiões onde os focos anteriores foram identificados, o ciclo de vida deste parasita persista com valores de prevalência baixos.

Salienta-se que, em vários ecossistemas dulçaquícolas do continente africano, estes dois parasitas utilizam os mesmos moluscos como HI. A fauna malacológica dulçaquícola de Portugal, Espanha, Córsega (França), Sardenha e Sicília (Itália) possui moluscos diferentes dos africanos, mas capazes de assegurar a sobrevivência destes parasitas.

Os novos dados obtidos, com o estudo do foco de esquistossomose humana e animal na Córsega, sugerem que estas doenças poderão regressar e instalar-se na Europa, com a grande probabilidade do aparecimento de novos casos e o risco de aumento da incidência nos países mediterrâneos. Esta previsão é corroborada:

1. Por flutuações climáticas que têm acontecido nos últimos anos, em que se tem registado, entre outras ocorrências, um aumento das temperaturas máximas que são mais adequadas ao desenvolvimento destes parasitas;

2. Pelo fluxo migratório sul-norte, de migrantes da África subsahariana, onde a esquistossomose humana é endémica, em particular a forma urogenital por S. haematobium;

3. E pela presença de moluscos aquáticos capazes de assegurar a sobrevivência deste parasita, nos países do sul da Europa, nomeadamente Portugal, Espanha, França e Itália. 